\title{
Correction to: Qualitative and Quantitative Performance Comparison of Recent Optimization Algorithms for Economic Optimization of the Heat Exchangers
}

\author{
Vivek K. Patel ${ }^{1}$ - Bansi D. Raja ${ }^{2}$. Vimal J. Savsani ${ }^{3}$ - Ali Rıza Yıldız ${ }^{4}$
}

Published online: 23 October 2020

(c) CIMNE, Barcelona, Spain 2020

\section{Correction to: \\ Archives of Computational Methods in Engineering https://doi.org/10.1007/s11831-020-09479-1}

The original online version of this article was revised to exclude the Ethics Disclosure. There is no conflict of interest in the sense referred to in academic publishing. The authors regret causing confusion and possible damage due to this unfortunate misunderstanding.

Publisher's Note Springer Nature remains neutral with regard to jurisdictional claims in published maps and institutional affiliations.

The original article can be found online at https://doi.org/10.1007/ s11831-020-09479-1.

Vimal J. Savsani

vimal.savsani@canadorecollege.ca

Vivek K. Patel

vivekp@sot.pdpu.ac.in

Bansi D. Raja

bansi14.raja@gmail.com

Ali Riza Yıldız

aliriza@uludag.edu.tr

1 Department of Mechanical Engineering, School

of Technology, Pandit Deendayal Petroleum University,

Gandhinagar, Gujarat, India

2 Department of Mechanical Engineering, Indus University, Ahmedabad, Gujarat, India

3 Department of Engineering, Canadore College, North Bay, ON, Canada

4 Automotive Engineering Department, Uludağ University, Görükle, Bursa, Turkey 